\title{
Altered Decorin Leads to Disrupted Endothelial Cell Function: A Possible Mechanism in the Pathogenesis of Fetal Growth Restriction?
}

Chui $A^{1}$, Murthi $P^{2,3}$, Gunatillake $T^{1,3}$, Brennecke S.P ${ }^{2,3}$, Ignjatovic ${ }^{4,5,6}$, Monagle P.T 4,5,6, Whitelock J.M ${ }^{7}$, and Said J.M ${ }^{1}$

${ }^{1}$ NorthWest Academic Centre, The University of Melbourne and Sunshine Hospital, St Albans 3021, Australia. ${ }^{2}$ Department of Perinatal Medicine, Pregnancy Research Centre, The Royal Women's Hospital and ${ }^{3}$ Department of Obstetrics and Gynaecology, The University of Melbourne, Parkville 3052, Australia. ${ }^{4}$ Murdoch Children's Research Institute and ${ }^{5}$ Department of Clinical Haematology and ${ }^{6}$ Department of Paediatrics, The Royal Children's Hospital and The University of Melbourne, Parkville 3052, Australia. ${ }^{7}$ Graduate School of Biomedical Engineering, University of New South Wales, Kensington 2033, Australia.

\section{Corresponding author:}

\section{Dr. Amy Chui}

NorthWest Academic Centre

The University of Melbourne and Sunshine Hospital

PO Box 294, 176 Furlong Road

St Albans 3021, Australia

Tel: +6138395 8088

Fax: +61 383958258

Email: akl.chui83@gmail.com 


\section{Abstract}

\section{Objective:}

Fetal growth restriction (FGR) is a key cause of adverse pregnancy outcome where maternal and fetal factors are identified as contributing to this condition. Idiopathic FGR is associated with altered vascular endothelial cell functions. Decorin (DCN) has important roles in the regulation of endothelial cell functions in vascular environments. $D C N$ expression is reduced in FGR. The objectives were to determine the functional consequences of reduced $D C N$ in a human microvascular endothelial cell line model (HMVEC), and to determine downstream targets of DCN and their expression in primary placental microvascular endothelial cells (PLECs) from control and FGR-affected placentae.

\section{Approach:}

Short-interference RNA was used to reduce DCN expression in HMVECs and the effect on proliferation, angiogenesis and thrombin generation was determined. A Growth Factor PCR Array was used to identify downstream targets of $D C N$. The expression of target genes in control and FGR PLECs was performed.

\section{Results:}

$D C N$ reduction decreased proliferation and angiogenesis but increased thrombin generation with no effect on apoptosis. The array identified three targets of $D C N$ : FGF17, IL18 and MSTN. Validation of target genes confirmed decreased expression of VEGFA, MMP9, EGFR1, IGFR1 and PLGF in HMVECs and PLECs from control and FGR pregnancies.

\section{Conclusions:}

Reduction of $D C N$ in vascular endothelial cells leads to disrupted cell functions. The targets of $D C N$ include genes that play important roles in angiogenesis and cellular growth. Therefore, differential expression of these may contribute to the pathogenesis of FGR and disease states in other microvascular circulations.

Key words: endothelial function; thrombosis; angiogenesis; gene expression; regulation 
62

63

64

65

66

67

68

69

70

71

72

73

74

75

76

77

78

79

80

81

82

83

84

85

86

87

88

89

90

91

92

93

94

95

96

97

98

99

100

101

102

103

104

105

106

107

\section{Introduction}

Fetal growth restriction (FGR) is defined as a neonatal birth-weight less than $10^{\text {th }}$ percentile for gestation together with evidence of fetal welfare compromise such as reduced amniotic fluid volume, increased head to abdomen circumference ratio and abnormal umbilical artery blood flow patterns [1]. FGR greatly increases the risk of perinatal complications including: fetal compromise in labour, fetal death in utero, neonatal morbidity and neonatal death [2-4]. Live born infants from pregnancies complicated by FGR have an increased risk of paediatric disorders such as cerebral dysfunction and learning difficulties, and of developing chronic adult onset diseases including: cardiovascular complications, type II diabetes, hypertension and ischemic heart disease [5-7]. Idiopathic FGR accounts for $70 \%$ of all cases of FGR and is believed to be associated with uteroplacental insufficiency [8], abnormal umbilical artery Doppler velocimetry [9], oligohydramnios [10] and fetal growth asymmetry [11]. Placental insufficiency may result from various factors including: constriction of the placental blood vessels due to reduction in vasodilator activity [12], incomplete cytotrophoblastic invasion of the maternal spiral arteries [13] or maldevelopment of the placental villous structures [14]. These factors result in increased resistance to blood flow within the placenta in both the maternal and fetal circulations, ultimately resulting in fetal hypoxia and acidosis.

Normal pregnancy represents a hypercoagulable state characterised by profound changes in haemostasis, such as, increased concentration of pro-coagulant factors, decreased anticoagulant activity and diminished fibrinolytic activity [15]. These changes result in increased thrombin generation in maternal plasma and ultimately, increased fibrin formation. These changes in haemostasis ensure the rapid and effective control of bleeding at the time of placental separation during delivery [15]. On the other hand, these changes may also predispose pregnant women to thrombosis and placental vascular complications. Despite this, thrombotic events are rare in uncomplicated pregnancies [16], indicating that thrombin generation must be tightly regulated in this scenario. In contrast, histological examinations of placentae from FGR pregnancies demonstrate increased fibrin deposition and thrombi in the vasculature, including uteroplacental and intervillous thrombosis, perivillous fibrin deposits and villous stem artery thrombosis [16], indicating an increase in overall thrombin activation [17]. The cause of the coagulation disturbance and increased placental thrombosis observed in idiopathic FGR pregnancies is unknown. However, since thrombin generation is significantly increased during normal pregnancy compared to the non-pregnant state [18], the excess thrombin is likely to be generated predominantly by the placenta, as demonstrated by decreased thrombin generation following placental separation during delivery [19].

Proteoglycans (PGs) are macromolecules comprising a core protein and at least one negatively charged polysaccharide glycosaminoglycan (GAG) side chain. The small leucine-rich proteoglycan (SLRP) family constitutes a network of signal regulation: being mostly extracellular, they are upstream of multiple signalling cascades, a major conduit 
108

109

110

111

112

113

114

115

116

117

118

119

120

121

122

123

124

125

126

127

128

129

130

131

of information for cellular responses and modulators of distinct pathways [20]. Decorin (DCN) belongs to the Class I SLRPs and can be substituted with one of either chondroitin or dermatan sulphate glycosaminoglycan (GAG) side chains. Previously, we have demonstrated an association between reduced placental $D C N$ expression and FGR [21], and propose that due to the many actions of DCN in vivo, this reduction contributes to the pathogenesis of FGR [22]. DCN and its side chain are involved in multiple biological functions such as, anticoagulation by binding to heparan cofactor II through a highly charged sequence [23], regulation of angiogenic growth factors such as, epidermal growth factor receptor (EGFR) and vascular endothelial growth factor (VEGF) [24] as well as regulation of basic cellular functions such as proliferation, migration and invasion [25, 26]. Mouse knockout models of $D C N$ demonstrate a range of pregnancy disorders including: pre-term birth [27], dystocia and delayed labour onset [28], as well as developmental anomalies in the offspring including: osteoporosis, osteoarthritis and corneal disease [29].

Since disturbances in many of these biological functions have been demonstrated in the pathogenesis of FGR, DCN may in fact play a major role in the pathogenesis of FGR. Therefore, in the present study, we investigated the effect of reduced $D C N$ gene expression on the function of microvascular endothelial cells. We also determined the down-stream target genes of $D C N$, in a placental microvascular endothelial cell environment and further validated the expression of these targets in control and FGRaffected placentae. 
132

133

134

135

136

137

138

139

140

141

142

143

144

145

146

147

148

149

150

151

152

153

154

155

156

157

158

159

160

161

162

163

164

165

166

167

168

169

170

171

172

173

174

175

176

177

Materials and methods (for additional methodology please refer to Supplementary Data)

\section{Cell lines}

The human microvascular endothelial primary cells from neonatal foreskin (HMVEC) were a kind gift from A/Prof. Grant Drummond (Department of Pharmacology, Monash University).

\section{Reduction of DCN expression by siRNA}

Four independent DCN siRNA oligonucleotides were obtained as "4-For-Silencing siRNA Duplexes"TM (Qiagen, Victoria, Australia). The DCN siRNAs showed no significant DNA sequence similarity to other genes in GenBank cDNA databases (data not shown).

\section{RNA extraction and cDNA preparation}

Total RNA was extracted from cultured HMVECs using PureLink RNA Mini-kits (Lifesciences, Victoria, Australia), as per manufacturer's instructions. cDNA was prepared in a two-step reaction using $2 \mu \mathrm{g}$ of total RNA.

\section{Real-Time PCR}

Quantification of DCN mRNA expression was determined by real-time PCR in an $\mathrm{ABI}$ Prism 7700 (Perkin-Elmer-Applied Biosystems, Victoria, Australia) as described previously [30].

\section{Western Immunoblotting}

Protein was homogenised and extracted from cultured HMVECs using RIPA Buffer (Pierce, Victoria, Australia). Immunoblotting was performed as described elsewhere [30]. The level of immunoreactive DCN protein relative to GAPDH was determined semi-quantitatively using scanning densitometry (Image Quant, New South Wales, Australia).

\section{HMVEC cell growth using xCELLigence}

HMVEC cell growth was assessed using the xCELLigence SP real-time system (Roche Diagnostics, Victoria, Australia) according to the manufacturer's instructions. The results were analysed using the RTCA Software 1.2 (Roche Diagnostics, Victoria, Australia) and GraphPad Prism 5 (GraphPad Software, California, USA).

\section{HMVEC network formation assays}

HMVEC network formation was assessed using the $\mu$-Slide Angiogenesis system (IBIDI, Victoria, Australia) as per manufacturer's instructions using10 $\mu$ l of neat Growth-Factor Reduced Matrigel ${ }^{\mathrm{TM}}$ (BD, Victoria, Australia). Photomicrographs of entire wells were taken in triplicates and branch points were counted by Wimasis Image Analysis.

\section{Thrombin Generation Assays}

HMVECs were plated into 96 well plates at a density of 5000 cells per well and transfected with DCN siRNAs and controls for $48 \mathrm{~h}$. Venous blood was collected from 
healthy blood donors $(n=40)$. Measurement of endogenous thrombin potential (ETP) by Calibrated Automated Thrombogram (CAT, Thrombinoscope, Stago Diagnostica, Victoria, Australia) was performed according to manufacturer's instructions. The ETP $(\mathrm{nM} /$ minute) was calculated using the Thrombinoscope software version 3.0.0.29.

\section{Human Growth Factors PCR Array}

The "Human Growth Factor" Taqman PCR array (Applied Biosystems, Victoria, Australia) for gene profiling was used to screen for downstream target genes of $D C N$, according to manufacturer's instructions. Candidate genes were prioritised based on level of gene expression i.e. at least 2-fold change in mRNA expression in siRNA treated cells when compared with NC.

\section{Feto-placental microvascular endothelial cell (PLEC) isolation}

Placentae from pregnancies complicated by idiopathic FGR $(n=3)$ and gestationmatched control $(n=3)$ pregnancies were collected with informed patient consent and approval from the Human Research and Ethics Committees of The Royal Women's Hospital, Melbourne. Ultrasound data were used to prospectively identify pregnancies complicated by FGR. The inclusion criteria of patients included in this study has been previously published [21].

Isolation of PLECs was undertaken according to the published methods of Dunk et al. 2012, using placental biopsies obtained from fresh placenta [31].

\section{Data Analysis}

All data in this study are described as mean \pm SEM and analysed by the GraphPad Prism 6 statistical software (GraphPad Software, California, USA). One-Way ANOVA was used to assess the differences in DCN mRNA and protein expression between siRNAtreated and control groups as well as in HMVEC functional assay studies. The MannWhitney $U$ test was used to analyse differences in gene expression between whole placenta and PLECs from control and FGR-affected placentae. A probability value of $<0.05$ was considered significant.

\section{Results}

\section{Reduced $D C N$ mRNA and protein expression following siRNA transfection in HMVECs}

Four independent siRNAs (designated as siRNA1-4), were designed to reduce $D C N$ expression in HMVECs. A non-siRNA transfected control (Mock) and a non-specific siRNA transfected control were used as negative controls. Fig $1 \mathrm{~A}$ revealed that treatment with siRNA2 and siRNA3 significantly reduced DCN mRNA expression compared to both the Mock and NC controls (Mock: $0.90 \pm 0.14$ and NC: $0.59 \pm 0.02$ vs. s2: $0.01 \pm 0.001$ and s3: $0.05 \pm 0.01, p<0.005, n=18$, One-Way ANOVA) at $48 \mathrm{~h}$ after transfection. A representative immunoblot for $\mathrm{DCN}(60 \mathrm{kDa})$ protein is shown in Fig $1 \mathrm{~B}$ for Mock, NC, siRNA2 and siRNA3, with the corresponding GAPDH. Semi-quantitative densitometry analysis revealed a decrease in immunoreactive $\mathrm{DCN}$ protein abundance 
in HMVECs treated with siRNA2 or siRNA3 compared with both the Mock and NC controls (Mock: $1.76 \pm 0.05$ and NC: $1.57 \pm 0.05$ vs. s2: $0.10 \pm 0.01$ and s3: $0.08 \pm 0.1$, $\mathrm{p}<0.05, \mathrm{n}=3$, One-Way ANOVA, Fig 1C).

\section{Reduced $D C N$ expression does not increase HMVEC apoptosis}

In order to determine that the reduction in DCN expression was not due to apoptosis as a result of treatment with siRNAs, the mRNA expression of three common apoptotic markers were analysed. Real-time PCR revealed that the mRNA expression of BCL2, p53 and CASPASE3 were not significantly different compared to the Mock or the NC controls ( $p>0.05, n=18$, One-Way ANOVA, data not shown).

\section{Reduced DCN expression decreases HMVEC proliferation and network formation but increases thrombin generation}

The effect on HMVEC proliferation after 48h DCN siRNA2 or siRNA3 treatment was determined using the xCELLigence system. Optimisation experiments confirmed that 5000 cells per well was the optimal density of cells to allow uninhibited cell proliferation (data not shown). Fig $2 \mathrm{~A}$ is a representative graph showing the cell index of HMVECs treated with siRNA compared to Mock or NC controls over $72 \mathrm{~h}$. At 48h post-siRNA transfection, the proliferation potential of the HMVECs were significantly decreased following $D C N$ reduction compared to both controls (Mock: $1.92 \pm 0.04$ and NC: $1.94 \pm 0.02$ vs. s2: $1.19 \pm 0.06$ and s3: $1.25 \pm 0.26, p<0.05, n=18$, One-Way ANOVA, Fig 2B).

The ability of HMVECs to form networks after DCN gene reduction was determined using the $\mu$-slide Angiogenesis system by IBIDI. Optimisation experiments to determine the optimal Growth-Factor Reduced Matrigel ${ }^{\mathrm{TM}}$ concentration and cell density were performed (data not shown). Following incubation for $48 \mathrm{~h}$, the cells were stained with calcien. Fig $2 \mathrm{C}$ shows representative images at $100 \mathrm{x}$ magnification taken after $48 \mathrm{~h} D C N$ siRNA transfection and reveals a qualitative decrease in HMVEC network formation compared to Mock or NC controls. Branch points were analysed and revealed that the network formation potential of HMVECs were significantly decreased following $D C N$ gene reduction compared to Mock and NC controls (Mock: $9.0 \pm 0.62$ and NC: $9.27 \pm 0.63$ vs. s2: $2.36 \pm 0.59$ and s3: $4.09 \pm 0.89, \mathrm{p}<0.01, \mathrm{n}=18$, One-Way ANOVA, Fig 2D).

The ETP of the HMVECs following the reduction in DCN gene expression was determined using the CAT system. A representative thrombin generation curve following reduction in DCN gene expression in HMVECs is depicted in Fig 2E. Reduction of $D C N$ expression by siRNA3 resulted in a significant increase in the ETP of the HMVECs compared with the Mock and NC controls (Mock: $1757.83 \pm 152.98$ and NC: $1749.28 \pm 40.66$ vs. s3: $1903.44 \pm 107.33, p<0.03, n=9$, One-Way ANOVA, Fig 2F).

\section{Identification of $D C N$ downstream target genes}

HMVECs were transfected with a NC control and siRNA3 and the "Human Growth Factors" Taqman PCR array was used to identify potential downstream target genes of $D C N$. The relative mRNA expression of the 84 genes after DCN mRNA and protein down-regulation is shown in Fig 3. The Y-axis represents the fold change for each of the 
84 genes normalised to the average expression of the five housekeeping genes included in the array. Genes that had an expression level above the positive two-fold change as indicated by a red line, was classified as genes with a fold increase. Conversely, genes that had an expression level below the negative two-fold change green line were classified as genes with a fold decrease in gene expression. The screening array identified three potential candidate downstream target genes of $D C N$ in HMVECs. These are fibroblast growth factor 17 (FGF17) with a fold increase of 2.4, interleukin 18 (IL18) with a fold decrease of 3.3 and myostatin (MSTN) with a fold decrease of -2.8 .

The mRNA expression of FGF17, IL18, and MSTN were further validated in HMVECs transfected with DCN siRNA independently (Fig 4). Increased expression of FGF17 (Mock: $1.04 \pm 0.19$ and NC: $1.29 \pm 0.14$ vs. s2: $4.62 \pm 0.76$ and $s 3: 4.77 \pm 0.46, p<0.05, n=9$, One-Way ANOVA) and decreased expression of MSTN (Mock: $1.00 \pm 0.06$ and NC: $1.81 \pm 0.18$ vs. s2: $0.51 \pm 0.19$ and s3: $0.43 \pm 0.09, p<0.05, n=9$, One-Way ANOVA) was confirmed. IL18 was not differentially expressed in DCN reduced HMVECs under independent validation (data not shown).

The mRNA expression of known target genes of $D C N$ from the published literature was also investigated in HMVECs following DCN gene reduction. As shown in Fig 5, the expression of VEGFA (Mock: $1.21 \pm 0.11$ and NC: $1.01 \pm 0.10$ vs. s2: $0.40 \pm 0.05$ and s3: $0.18 \pm 0.07, \mathrm{p}<0.05, \mathrm{n}=9$, One-Way ANOVA), MMP9 (Mock: 1.19 \pm 0.21 and NC: 0.85 \pm 0.11 vs. $s 2: 0.14 \pm 0.01$ and $s 3: 0.03 \pm 0.02, \mathrm{p}<0.01, \mathrm{n}=9$, One-Way ANOVA), EGFR1 (Mock: $0.76 \pm 0.22$ and NC: $1.00 \pm 0.01$ vs. s2: $0.26 \pm 0.03$ and s3: $0.18 \pm 0.03, p<0.05, n=9$, One-Way ANOVA), IGFR1 (Mock: $0.80 \pm 0.06$ and NC: $1.01 \pm 0.11$ vs. s2: $0.41 \pm 0.06$ and s3: $0.29 \pm 0.0 .03, \mathrm{p}<0.05, \mathrm{n}=9$, One-Way ANOVA) and PLGF (Mock: $1.07 \pm 0.27$ and NC: $1.96 \pm 0.06$ vs. $s 2: 0.23 \pm 0.02$ and $s 3: 0.28 \pm 0.05, p<0.03, n=9$, One-Way ANOVA) were significantly reduced following treatment with DCN siRNA2 or siRNA3 compared with the Mock or NC controls. The mRNA expression of MMP2, HIF1A, Thrombospondin1, TIMP3, TLR2 and TLR4 were not significantly different between the two groups (data not shown).

\section{Validation of $D C N$ and its downstream target genes in control and FGR-affected primary placental endothelial cells (PLECs)}

The mRNA expression of DCN and its targets were validated in PLECs cultured from control and FGR-affected placentae. Shown in Fig 6A, the mRNA expression of DCN was significantly decreased in PLECs cultured from FGR-affected placentae compared with controls (Control PLEC: $1.04 \pm 0.14$ vs. FGR PLEC: $0.21 \pm 0.06, p<0.003, n=3$ each, Mann-Whitney U Test). In Fig 6B-F, significant decreases in mRNA expression was also observed for EGFR1 (Control PLEC: $1.04 \pm 0.11$ vs. FGR PLEC: $0.26 \pm 0.06, p<0.003$, $\mathrm{n}=3$ each, Mann-Whitney U Test), IGFR1 (Control PLEC: $1.05 \pm 0.15$ vs. FGR PLEC: $0.45 \pm 0.05, \mathrm{p}<0.005, \mathrm{n}=3$ each, Mann-Whitney U Test), PLGF (Control PLEC: $1.18 \pm 0.32$ vs. FGR PLEC: $0.32 \pm 0.12, \mathrm{p}<0.05, \mathrm{n}=3$ each, Mann-Whitney $U$ Test) and VEGFA (Control PLEC: $1.52 \pm 0.60$ vs. FGR PLEC: $0.33 \pm 0.07, p<0.05, n=3$ each, Mann-Whitney U Test) between control and FGR-affected PLECs. In contrast, the mRNA expression of MMP9 was significantly increased in FGR-affected PLECs compared with controls 
316 (Control PLEC: $1.09 \pm 0.21$ vs. FGR PLEC: $2.51 \pm 0.40, \mathrm{p}<0.03, \mathrm{n}=3$ each, Mann-Whitney $U$ Test). These results are consistent with those observed in the previous validation experiments using HMVECs (with the exception of FGF17 and MSTN which were not expressed in PLECs). 


\section{Discussion}

In this current study we focused on $D C N$, a small leucine-rich proteoglycan, and demonstrate for the first time that reduction of $D C N$ gene expression in a primary human microvascular endothelial cell type (HMVEC) results in a significant decrease in HMVEC proliferation, network formation and thrombin generation. We also revealed differential expression of $D C N$ target genes in FGR-affected primary placental microvascular endothelial cells (PLECs). The results reveal a consistency in the expression patterns of VEGFA, MMP9, EGFR1, IGFR1 and PLGF.

In tumour cells, $D C N$ has been shown to command a powerful anti-tumorigenic signal by potently repressing and attenuating tumour cell proliferation, survival, migration and angiogenesis via binding to EGFR and IGFR [32]. In addition, DCN has also been described as an angiostatic agent in tumour cells via a reduction in VEGF and MMP9 production [33]. In extravillous trophoblast cells, $D C N$ has been shown to be an antagonist of proliferation and migration, via suppression of VEGFR2 and EGFR1 [25], as well as extravillous differentiation and angiogenesis by blocking activation of p38 MAPK, and ERK pathways by VEGFA [34].

In this study, reduction of $D C N$ expression resulted in decreased HMVEC proliferation and network formation, potentially due to the subsequent downstream decrease in the expression of EGFR1, IGFR1 and VEGFR. Inadequate fetal vessel angiogenesis and proliferation is consistent with histological observations of the FGR placenta [14]. Thus $D C N$ appears to mediate a pro-angiogenic role in HMVECs and deficiency of DCN results in inhibition of angiogenesis and proliferation. Our findings are in contrast with those in the cancer literature but are supported by other studies demonstrating a proangiogenic and pro-proliferative response of $D C N$, primarily on normal, non-tumorigenic endothelial cells [35]. Furthermore, evidence suggests that $D C N$-deficient mice have diminished growth of vessels [36].

Despite the multiple biological actions of $D C N$ on a variety of cell types, the nature of the cell surface receptors responsible for $D C N$ action has remained elusive in many cases. For example, DCN was shown to interact with EGFR in a squamous cell carcinoma line, leading to the triggering of a signal cascade, and finally growth suppression associated with a retardation of EGFR recycling to the cell surface [37-41]. $D C N$ also interacts with IGFR in endothelial cells, leading to its phosphorylation, followed by a down-regulation of the receptor, resulting in cell survival [25]. Therefore, the dichotomous effect reported for $D C N$ on endothelial cells and the previously described function on tumourigenesis creates a scenario where $D C N$ may be able to differentially modulate angiogenesis.

Another plausible explanation for the diverse functions of $D C N$ is that small leucine-rich proteoglycans undergo a dimer-monomer transition that would expose key sites involved in specific bindings; therefore their functional activity in vivo would be regulated by the structure of DCN in that particular cell type and by the intrinsic affinity of DCN for 
its cognate receptor [20,42]. In addition, the binding and function of DCN to specific receptors also depends on whether it is a GAG-bound DCN or just the core protein [43].

The differences between the cells in the previous published work are that both tumour cells and extravillous trophoblast cells are highly proliferative, invasive and angiogenic where $D C N$ negatively regulates angiogenesis and proliferation in highly proliferative, invasive, and angiogenic environment to prevent aberrant tumour growth. However, in this study, we used HMVECs, which represents normal microvascular environment whose primary function is to form networks during vascular development. Therefore, it is possible that in a normal microvasculature environment, where a balanced level of angiogenesis and proliferation is required, $D C N$ may act positively to regulate proliferation and angiogenesis.

Thrombin generation is a global haemostatic functional assay used widely to measure hypo- or hyper-coagulability and reflects the interplay of all haemostatic factors in plasma/blood. The ETP provides an in vitro measure of the overall ability to generate thrombin, the final crucial stage of haemostasis and is therefore, the best assessment of global haemostasis [44]. The ETP quantifies the visual differences between the thrombin generation curves and allows for statistical analysis. This study has demonstrated a modest, but statistically significant increase in thrombin generation following reduction in $D C N$ expression in HMVECs which implies a hyper-coagulable state with $D C N$ down-regulation. This is consistent with observations in the FGR placenta where increased intervillous thrombi are observed [9]. Delorme et al (1998) isolated and characterized the glycosaminoglycan, dermatan sulphate (DS), in term human placenta and revealed that DS was predominantly present on the protein core of DCN. Since DS catalyzes the inhibition of thrombin by heparin-cofactor II [45], a reduction in $D C N$ expression in HMVECs could result in an increase in thrombin generation [19]. Although the difference observed is small, this difference in a global setting could potentially lead to significant changes to overall thrombin generation in the placental microvascular system. It is therefore plausible that the observed increase in localised placental intravascular thrombosis is due to a decrease in the expression of $D C N$ in human FGR-affected placentae [21].

Since it appears that the molecular function of DCN is also highly dependent on the structure, function and sulfation/glycosylation sites of both the protein core and the GAG side chain $[20,46,47]$, investigations into the exact structural moiety of DCN in both the control and FGR-affected placenta could reveal important information about the role of DCN in the pathogenesis of FGR.

In summary, this study has shown that reduced expression of the proteoglycan $D C N$ in a microvascular endothelial cell line results in altered endothelial cell functions such as proliferation and network formation as well as an increase in global thrombin generation without affecting apoptosis. These alterations may be a consequence of altered growth factor expression as a result of downstream regulation by $D C N$ or via a direct local effect of reduced $D C N$ and dermatan sulphate abundance. These findings provide valuable insight into the endothelial milieu in the growth restricted placenta. This raises 
413 the possibility that increased $D C N$ expression may improve the anti-angiogenic and 414 thrombotic changes observed within the placental vasculature in FGR. Moreover, the 415 findings of this study have implications beyond pregnancy and suggest that $D C N$ may 416 play important roles in the pathogenesis of other disease states in microvascular 417 circulations through these angiogenic, thrombotic and growth factor mediated pathways. In addition, investigation of the relative roles of the DCN protein core versus the GAG 420 side chain in these functions may assist in revealing the logical therapeutic approaches to the treatment of FGR and related vascular pathologies. 
423

424

425

426

427

428

429

430

431

\section{Acknowledgements}

a) The authors would like to thank Diagnostica Stago (Australia) for the loan of the Calibrated Automated Thrombogram.

b) Sources of funding: this work was supported by a National Health and Medical Research Council (NH\&MRC) Project Grant, Australia (Application: 1004952). 


\section{References}

[1]. Mongelli M, Gardosi J. Fetal growth. Curr Opin Obstet Gynecol. 2000;12(2):1115.

[2]. Mclntire DD, Bloom SL, Casey BM, Leveno KJ. Birth weight in relation to morbidity and mortality among newborn infants. N Engl J Med. 1999;340(16):1234-8. [3]. Kramer MS, Olivier M, McLean FH, Willis DM, Usher RH. Impact of intrauterine growth retardation and body proportionality on fetal and neonatal outcome. Pediatrics. 1990;86(5):707-13.

[4]. Froen JF, Gardosi JO, Thurmann A, Francis A, Stray-Pedersen B. Restricted fetal growth in sudden intrauterine unexplained death. Acta Obstet Gynecol Scand. 2004;83(9):801-7.

[5]. Rosso IM, Cannon TD, Huttunen T, Huttunen MO, Lonnqvist J, Gasperoni TL. Obstetric risk factors for early-onset schizophrenia in a Finnish birth cohort. Am $\mathrm{J}$ Psychiatry. 2000;157(5):801-7.

[6]. Godfrey KM, Barker DJ. Fetal nutrition and adult disease. Am J Clin Nutr. 2000;71(5 Suppl):1344S-52S.

[7]. Godfrey KM, Barker DJ. Fetal programming and adult health. Public Health Nutr. 2001;4(2B):611-24.

[8]. Ghidini A. Idiopathic fetal growth restriction: a pathophysiologic approach. Obstet Gynecol Surv. 1996;51(6):376-82.

[9]. Salafia CM, Pezzullo JC, Minior VK, Divon MY. Placental pathology of absent and reversed end-diastolic flow in growth-restricted fetuses. Obstet Gynecol. 1997;90(5):830-6.

[10]. Volante E, Gramellini D, Moretti S, Kaihura C, Bevilacqua G. Alteration of the amniotic fluid and neonatal outcome. Acta Biomed. 2004;75 Suppl 1:71-5.

[11]. Vik T, Markestad T, Ahlsten G, Gebre-Medhin M, Jacobsen G, Hoffman HJ, et al. Body proportions and early neonatal morbidity in small-for-gestational-age infants of successive births. Acta Obstet Gynecol Scand Suppl. 1997;165:76-81.

[12]. Chang TC, Robson SC, Spencer JA, Gallivan S. Identification of fetal growth retardation: comparison of Doppler waveform indices and serial ultrasound measurements of abdominal circumference and fetal weight. Obstet Gynecol. 1993;82(2):230-6.

[13]. Gagnon R. Placental insufficiency and its consequences. Eur J Obstet Gynecol Reprod Biol. 2003;110 Suppl 1:S99-107.

[14]. Kingdom J, Huppertz B, Seaward G, Kaufmann P. Development of the placental villous tree and its consequences for fetal growth. Eur J Obstet Gynecol Reprod Biol. 2000;92(1):35-43.

[15]. Brenner B. Haemostatic changes in pregnancy. Thromb Res. 2004;114(5-6):40914.

[16]. Lanir N, Aharon A, Brenner B. Haemostatic mechanisms in human placenta. Best practice \& research Clinical haematology. 2003;16(2):183-95. Epub 2003/05/24. [17]. Kingdom JC, Kaufmann P. Oxygen and placental villous development: origins of fetal hypoxia. Placenta. 1997;18(8):613-21; discussion 23-6. 
476

477

478

479

480

481

482

483

484

485

486

487

488

489

490

491

492

493

494

495

496

497

498

499

500

501

502

503

504

505

506

507

508

509

510

511

512

513

514

515

516

517

518

519

520

[18]. Uszynski M. Generation of thrombin in blood plasma of non-pregnant and pregnant women studied through concentration of thrombin-antithrombin III complexes. Eur J Obstet Gynecol Reprod Biol. 1997;75(2):127-31.

[19]. Delorme MA, Xu L, Berry L, Mitchell L, Andrew M. Anticoagulant dermatan sulfate proteoglycan (decorin) in the term human placenta. Thromb Res. 1998;90(4):147-53. Epub 1998/08/06.

[20]. Schaefer L, lozzo RV. Biological functions of the small leucine-rich proteoglycans: from genetics to signal transduction. J Biol Chem. 2008;283(31):213059. Epub 2008/05/09.

[21]. Swan BC, Murthi P, Rajaraman G, Pathirage NA, Said JM, Ignjatovic V, et al. Decorin expression is decreased in human idiopathic fetal growth restriction. Reprod Fertil Dev. 2010;22(6):949-55. Epub 2010/07/02.

[22]. Said JM. The role of proteoglycans in contributing to placental thrombosis and fetal growth restriction. J Pregnancy. 2011;2011:928381. Epub 2011/04/15.

[23]. Chen J, Liu J. Characterization of the structure of antithrombin-binding heparan sulfate generated by heparan sulfate 3-O-sulfotransferase 5 . Biochim Biophys Acta. 2005;1725(2):190-200. Epub 2005/08/16.

[24]. Reinboth B, Thomas J, Hanssen E, Gibson MA. Beta ig-h3 interacts directly with biglycan and decorin, promotes collagen $\mathrm{VI}$ aggregation, and participates in ternary complexing with these macromolecules. J Biol Chem. 2006;281(12):7816-24. Epub 2006/01/26.

[25]. lacob D, Cai J, Tsonis M, Babwah A, Chakraborty C, Bhattacharjee RN, et al. Decorin-mediated inhibition of proliferation and migration of the human trophoblast via different tyrosine kinase receptors. Endocrinology. 2008;149(12):6187-97.

[26]. Xu G, Guimond MJ, Chakraborty C, Lala PK. Control of proliferation, migration, and invasiveness of human extravillous trophoblast by decorin, a decidual product. Biol Reprod. 2002;67(2):681-9.

[27]. Calmus ML, Macksoud EE, Tucker R, lozzo RV, Lechner BE. A mouse model of spontaneous preterm birth based on the genetic ablation of biglycan and decorin. Reproduction. 2011;142(1):183-94. Epub 2011/04/20.

[28]. Meyerson M, Counter CM, Eaton EN, Ellisen LW, Steiner P, Caddle SD, et al. hEST2, the putative human telomerase catalytic subunit gene, is up-regulated in tumor cells and during immortalization. Cell. 1997;90(4):785-95. Epub 1997/08/22. [29]. Gimbrone MA, Jr., Fareed GC. Transformation of cultured human vascular endothelium by SV40 DNA. Cell. 1976;9(4 PT 2):685-93. Epub 1976/12/01.

[30]. Chui A, Zainuddin N, Rajaraman G, Murthi P, Brennecke SP, Ignjatovic V, et al. Placental syndecan expression is altered in human idiopathic fetal growth restriction. Am J Pathol. 2012;180(2):693-702. Epub 2011/12/06.

[31]. Dunk CE, Roggensack AM, Cox B, Perkins JE, Asenius F, Keating S, et al. A distinct microvascular endothelial gene expression profile in severe IUGR placentas. Placenta. 2012;33(4):285-93. Epub 2012/01/24.

[32]. Neill T, Painter H, Buraschi S, Owens RT, Lisanti MP, Schaefer L, et al. Decorin antagonizes the angiogenic network: concurrent inhibition of Met, hypoxia inducible factor 1alpha, vascular endothelial growth factor $A$, and induction of thrombospondin-1 and TIMP3. J Biol Chem. 2012;287(8):5492-506. Epub 2011/12/24. 
[33]. Neill T, Schaefer L, lozzo RV. Decorin: a guardian from the matrix. Am J Pathol. 2012;181(2):380-7. Epub 2012/06/28.

[34]. Lala N, Girish GV, Cloutier-Bosworth A, Lala PK. Mechanisms in decorin regulation of vascular endothelial growth factor-induced human trophoblast migration and acquisition of endothelial phenotype. Biol Reprod. 2012;87(3):59. Epub 2012/06/16. [35]. Nelimarkka L, Salminen H, Kuopio T, Nikkari S, Ekfors T, Laine J, et al. Decorin is produced by capillary endothelial cells in inflammation-associated angiogenesis. Am J Pathol. 2001;158(2):345-53. Epub 2001/02/13.

[36]. Schonherr E, Sunderkotter C, Schaefer L, Thanos S, Grassel S, Oldberg A, et al. Decorin deficiency leads to impaired angiogenesis in injured mouse cornea. $J$ Vasc Res. 2004;41(6):499-508. Epub 2004/11/06.

[37]. Csordas G, Santra M, Reed CC, Eichstetter I, McQuillan DJ, Gross D, et al. Sustained down-regulation of the epidermal growth factor receptor by decorin. A mechanism for controlling tumor growth in vivo. J Biol Chem. 2000;275(42):32879-87. Epub 2000/07/27.

[38]. Iozzo RV, Moscatello DK, McQuillan DJ, Eichstetter I. Decorin is a biological ligand for the epidermal growth factor receptor. J Biol Chem. 1999;274(8):4489-92. Epub 1999/02/13.

[39]. Patel S, Santra M, McQuillan DJ, lozzo RV, Thomas AP. Decorin activates the epidermal growth factor receptor and elevates cytosolic Ca2+ in A431 carcinoma cells. J Biol Chem. 1998;273(6):3121-4. Epub 1998/03/07.

[40]. Santra M, Reed CC, lozzo RV. Decorin binds to a narrow region of the epidermal growth factor (EGF) receptor, partially overlapping but distinct from the EGF-binding epitope. J Biol Chem. 2002;277(38):35671-81. Epub 2002/07/10.

[41]. Zhu JX, Goldoni S, Bix G, Owens RT, McQuillan DJ, Reed CC, et al. Decorin evokes protracted internalization and degradation of the epidermal growth factor receptor via caveolar endocytosis. J Biol Chem. 2005;280(37):32468-79. Epub 2005/07/05.

[42]. McEwan PA, Scott PG, Bishop PN, Bella J. Structural correlations in the family of small leucine-rich repeat proteins and proteoglycans. J Struct Biol. 2006;155(2):294305. Epub 2006/08/04.

[43]. Fiedler LR, Schonherr E, Waddington R, Niland S, Seidler DG, Aeschlimann D, et al. Decorin regulates endothelial cell motility on collagen I through activation of insulin-like growth factor I receptor and modulation of alpha2beta1 integrin activity. $J$ Biol Chem. 2008;283(25):17406-15. Epub 2008/04/17.

[44]. Al Dieri R, Peyvandi F, Santagostino E, Giansily M, Mannucci PM, Schved JF, et al. The thrombogram in rare inherited coagulation disorders: its relation to clinical bleeding. Thromb Haemost. 2002;88(4):576-82. Epub 2002/10/04.

[45]. Tollefsen DM, Pestka CA, Monafo WJ. Activation of heparin cofactor II by dermatan sulfate. J Biol Chem. 1983;258(11):6713-6. Epub 1983/06/10.

[46]. Moreth K, lozzo RV, Schaefer L. Small leucine-rich proteoglycans orchestrate receptor crosstalk during inflammation. Cell Cycle. 2012;11(11):2084-91. Epub 2012/05/15.

[47]. Schaefer L, Schaefer RM. Proteoglycans: from structural compounds to signaling molecules. Cell Tissue Res. 2010;339(1):237-46. Epub 2009/06/11. 
567

568

569

570

571

572

573

574

575

576

577

578

579

580

581

582

583

584

585

586

587

588

589

590

591

592

593

594

595

596

597

598

599

600

601

602

603

604

605

606

607

608

609

610

611

612

\section{Figure legends}

Figure 1 Reduced DCN mRNA and protein expression following siRNA transfection in HMVECs

A. Real-time PCR was performed on HMVECs transfected with Mock and NC control, DCN siRNA1, 2, 3 and 4 oligonucleotides, over 24, 48 and 72 hours. Relative quantification of DCN mRNA expression relative to the housekeeping gene $18 S \mathrm{SRNA}$ was calculated using the $2-\Delta \Delta C T$ method. * $=$ Significance, $\mathrm{p}<0.05, \mathrm{n}=18$, One-Way ANOVA. The $\mathrm{Y}$-axis represents the mRNA expression of decorin relative to $18 S \mathrm{SRNA}$. B. Protein was extracted from cultured HMVECs after transfection with Mock and NC control and DCN siRNA2 or siRNA3 oligonucleotides for 48 hours. Protein samples $(25 \mu \mathrm{g})$ were electrophoresed on a $10 \%$ SDS-PAGE gel and transferred to a PVDF membrane. Immunoblotting was performed and chemiluminescent detection of the $60 \mathrm{kDa} \mathrm{DCN}$ protein is shown in the upper panel. Lanes 1, 2, 3 and 4 represents the Mock and NC control, DCN siRNA3 and siRNA4 transfected samples in HMVECs, respectively. The lower panel is GAPDH showing the protein load for all samples. C. The densitometric values normalised to GAPDH for DCN immunoreactive protein after siRNA transfection in HMVECs is shown. * = Significance, $p<0.05, n=3$, One-Way ANOVA. The $Y$-axis represents the densitometric values of decorin protein relative to GAPDH.

\section{Figure 2 Reduced DCN expression decreases HMVEC proliferation and network} formation but increases thrombin generation

A. HMVEC proliferation was determined using XCELLigence (Roche Diagnostics, USA). A representative graph showing the cell index (Y-axis) of HMVECs transfected with Mock, NC, DCN siRNA2 or siRNA3 over a $72 \mathrm{~h}$ time period is presented here.

B. The total effect of $D C N$ gene reduction on HMVEC proliferation was determined quantitatively at the $48 \mathrm{~h}$ time-point. ${ }^{*}=$ Significance, $\mathrm{p}<0.05, \mathrm{n}=18$, One-Way ANOVA. The $\mathrm{Y}$-axis represents the cell index over time.

C. Representative images of HMVEC network formation after 48h Mock, NC, and DCN siRNA2 or siRNA3 transfection. Cells were stained with calcien and images were taken using a fluorescent microscope (CellR, Olympus, Japan). Magnification of all images is at $100 \mathrm{X}$, scale bars represent $50 \mu \mathrm{m}$.

D. The ability for HMVECs to form networks after transfection with Mock, NC, DCN siRNA2 or siRNA3 over a 48h time period was determined using IBIDI angiogenesis slides (IBIDI, Germany). The total number of branch points was determined using the Wimasis Image Analysis tool. * = Significance, $\mathrm{p}<0.05, \mathrm{n}=18$, One-Way ANOVA. The $\mathrm{Y}$ axis represents the number of branch points at $48 \mathrm{~h}$.

E. A representative thrombin generation curve showing the effect of $D C N$ gene reduction in HMVECs is shown here. The Y-axis represents the amount of thrombin generated relative to time.

F. A statistical representation of the effect of reduced $D C N$ expression on the ETP of HMVECs is shown. ${ }^{*}=$ Significance, $\mathrm{p}<0.05, \mathrm{n}=9$, One-Way ANOVA. The $\mathrm{Y}$-axis represents the amount of thrombin generated relative to time. 
613

614

615

616

617

618

619

620

621

622

623

624

625

626

627

628

629

630

631

632

633

634

635

636

637

638

639

640

641

642

643

644

645

646

647

648

Figure 3 Identification of $D C N$ downstream target genes after siRNA transfection RNA was extracted from HMVECs transfected with DCN siRNA, transcribed into first strand CDNA, and the Taqman Growth Factors Real-time PCR array was performed for gene profiling. The 84 pre-dispensed genes, which included a panel of housekeeping genes, were amplified for 40 cycles of denaturation and primer extension. Gene expression values (fold change above or below threshold value of 2) were subsequently calculated for the $D C N$ siRNA-treated plate, relative to the NC control and normalised to the housekeeping gene panel ( $x$-axis). The red line shows the threshold value at 2 and the green line shows the threshold value at -2 . Values greater than 2 were termed a fold increase and those less than -2 were considered a fold decrease.

\section{Figure 4 Validation of candidate $D C N$ downstream target genes in cultured HMVECS} CDNA from HMVECs transfected with Mock and NC controls, and DCN siRNA2 or siRNA3 were amplified for 40 cycles using pre-validated Taqman gene expression assays for FGF17 (A) and MSTN (B). The 18S rRNA housekeeping gene was used for relative quantification according to the $2^{-\Delta \Delta C T}$ method of Livak and Schmittgen (2001). The NC control was used as the calibrator. ${ }^{*}=$ Significance, $p<0.05, n=9$, One-Way ANOVA. The Y-axis represents the gene expression relative to $18 S$ rRNA.

Figure 5 Expression of candidate target genes of $D C N$ in HMVECs after reduction in $D C N$ expression

The mRNA expression of VEGFA (A), MMP9 (B), EGFR (C), IGFR1

(D) and PLGF (E) was determined by real-time PCR using pre-validated

Taqman gene expression assays. The 18S rRNA housekeeping gene was used for relative quantification according to the $2^{-\Delta \Delta C T}$ method of Livak and Schmittgen (2001). The NC control was used as the calibrator. ${ }^{*}=$ Significance, $p<0.05, n=9$, One-Way ANOVA. The $\mathrm{Y}$-axis represents the gene expression relative to $18 \mathrm{~S}$ rRNA.

Figure 6 Expression of $D C N$ and its target genes in control and FGR-affected primary placental endothelial cells

The mRNA expression of DCN, EGFR1, IGFR1, PLGF, VEGFA and MMP9 was determined by real-time PCR according to the $2^{-\triangle \triangle C T}$ method of Livak and Schmittgen (2001). The control PLECs were used as the calibrator. ${ }^{*}=$ Significance, $p<0.05$, MannWhitney $\mathrm{U}$ Test. The $\mathrm{Y}$-axis represents the gene expression relative to $18 \mathrm{~S}$ rRNA. 
649

650

651

652

653

654

655

656

657

658

659

660

661

662

663

664

665

666

667

668

669

670

671

672

673

674

675

676

677

678

679

\section{Author Contributions}

1. Chui, $A$ - I declare that I participated in the study design, performing of all experiments, data analysis and interpretation, writing of manuscript and final approval of manuscript for submission.

2. Murthi, P-I declare that I participated in the study concept and design, performed the isolation of PLECs, interpretation of data, critical review of manuscript drafts and final approval of manuscript for submission.

3. Gunatillake, $\mathrm{T}-\mathrm{I}$ declare that I participated in and performed some of the thrombin experiments, data analysis and interpretation, critical review and final approval of manuscript for submission.

4. Brennecke, SP - I declare that I participated in the study concept and design, interpretation of data, critical review of manuscript drafts and final approval of manuscript for submission.

5. Ignjatovic, $\mathrm{V}-$ I declare that I participated in the study concept and design, performed some of the thrombin experiments, interpretation and analysis of data, critical review of manuscript drafts and final approval of manuscript for submission.

6. Monagle, PT - I declare that I participated in the study concept and design, interpretation of data, critical review of manuscript drafts and final approval of manuscript for submission.

7. Whitelock, JM - I declare that I participated in the study concept and design, interpretation of data, critical review of manuscript drafts and final approval of manuscript for submission.

8. Said, JM - I declare that I participated in the study concept and design, interpretation of data, critical review of manuscript drafts and final approval of manuscript for submission. 
Figure 1

A.

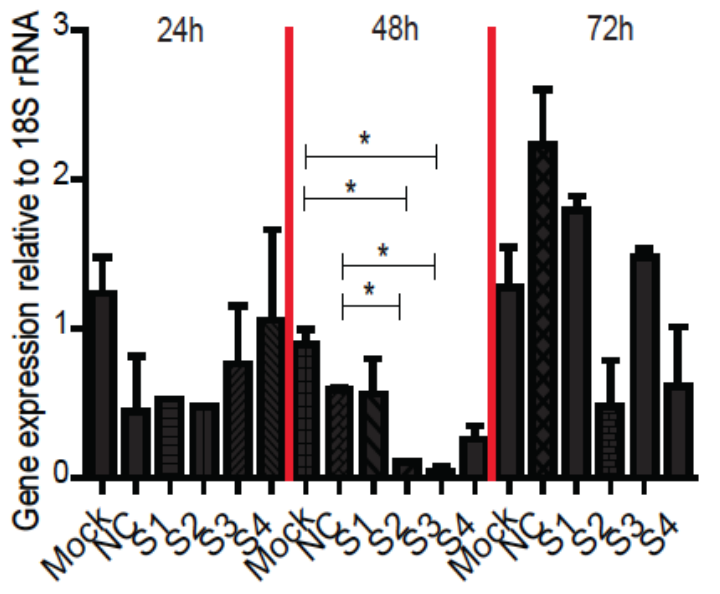

C.

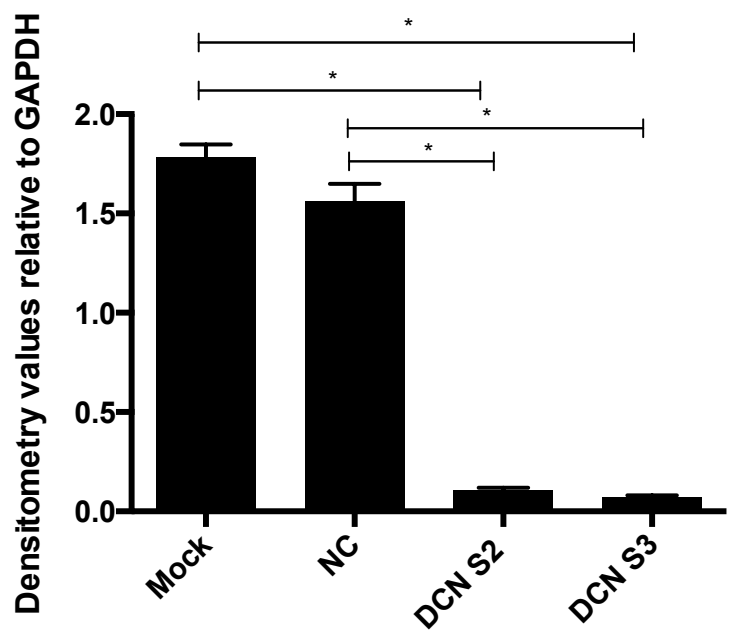

B.

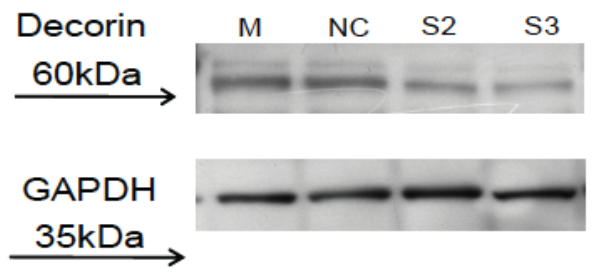


Figure 2
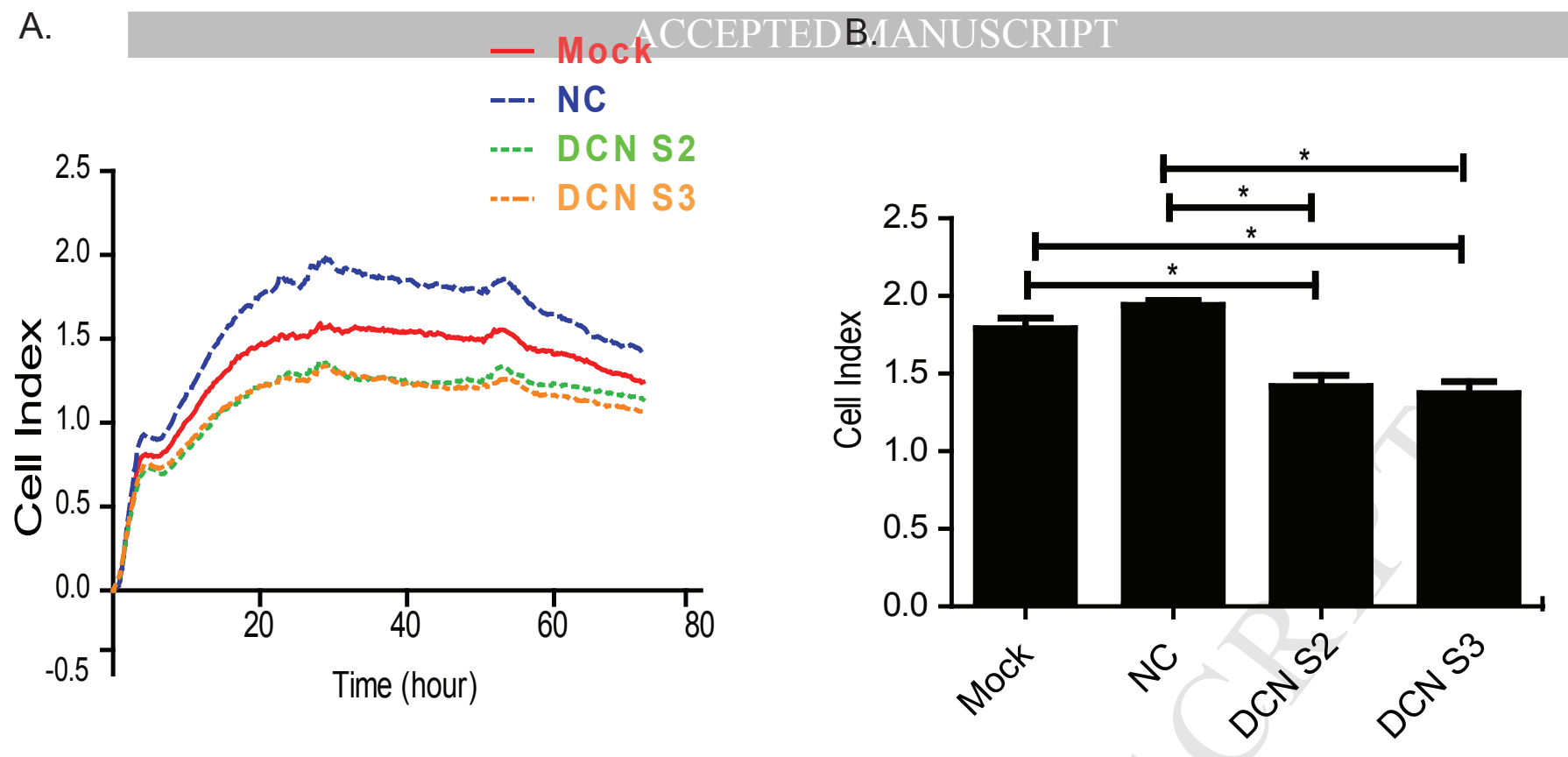

C.

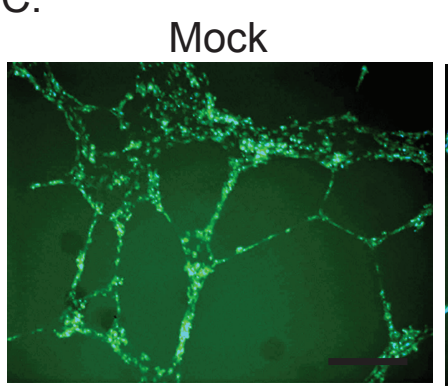

DCN S2
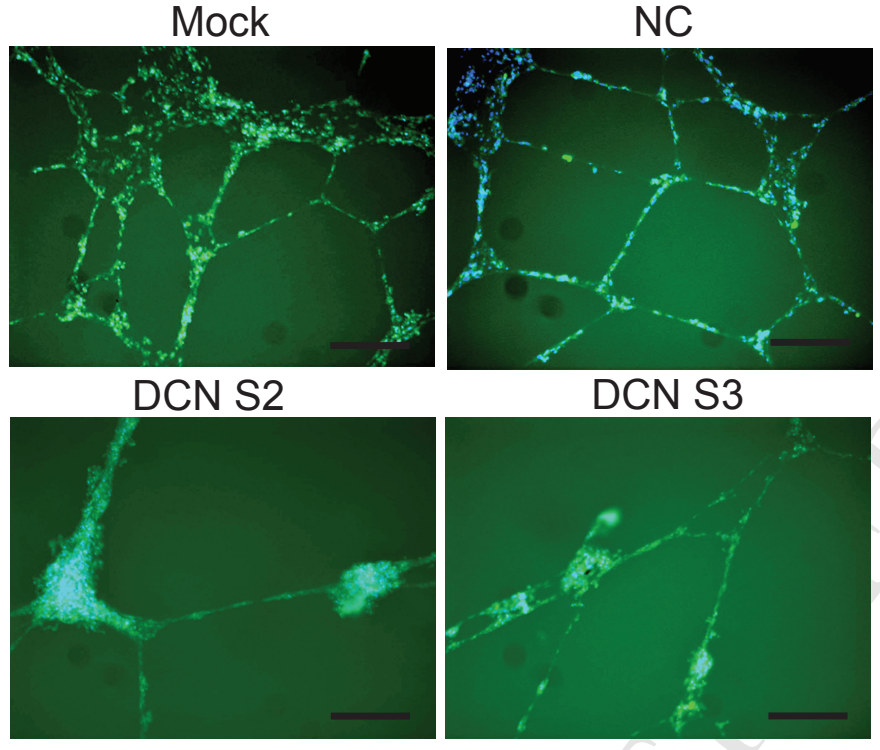

DCN S3

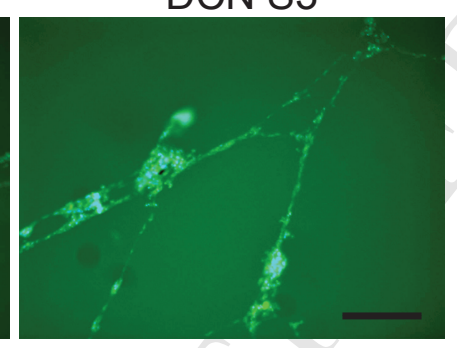

D.

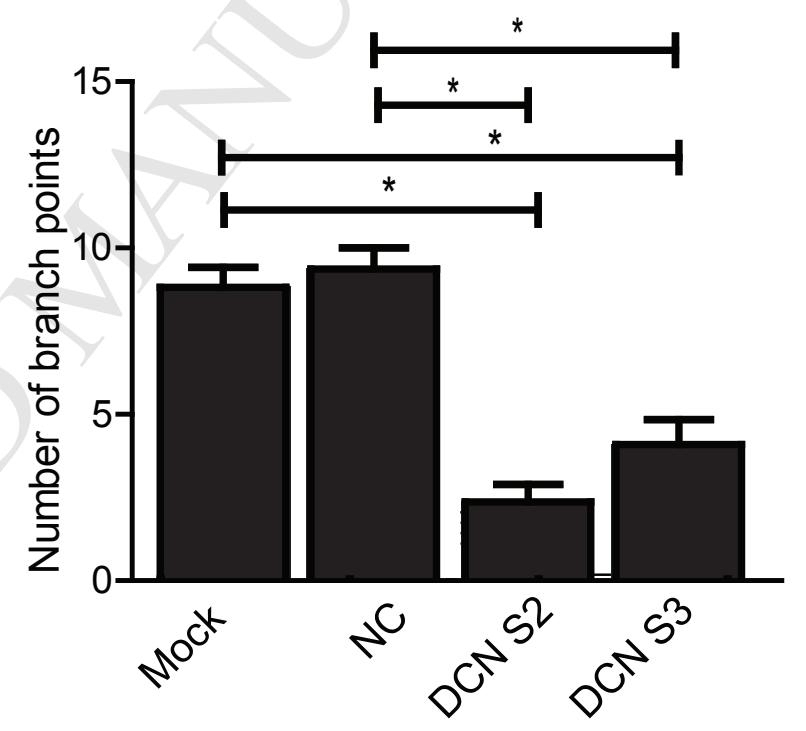

E.

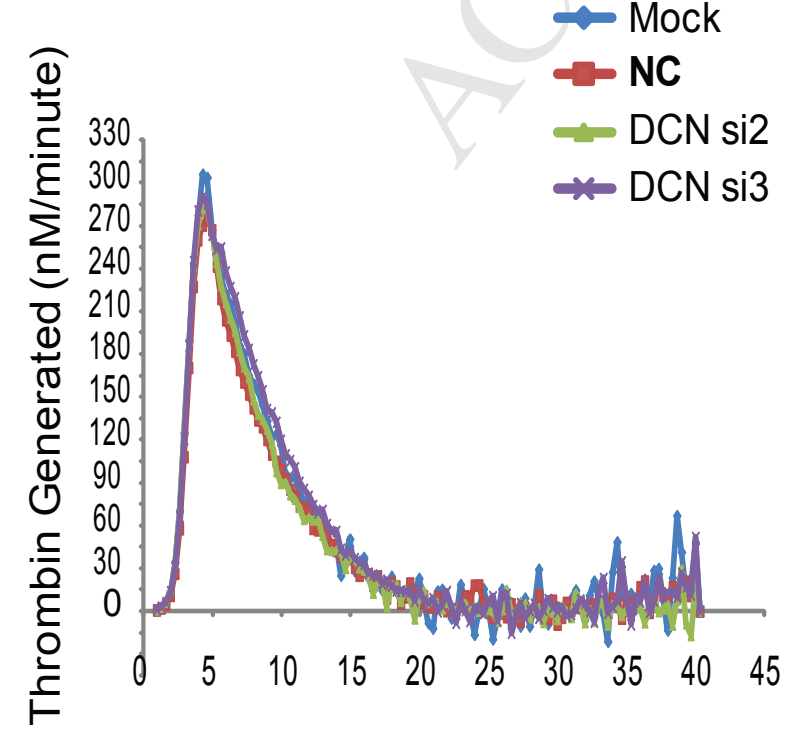

F.

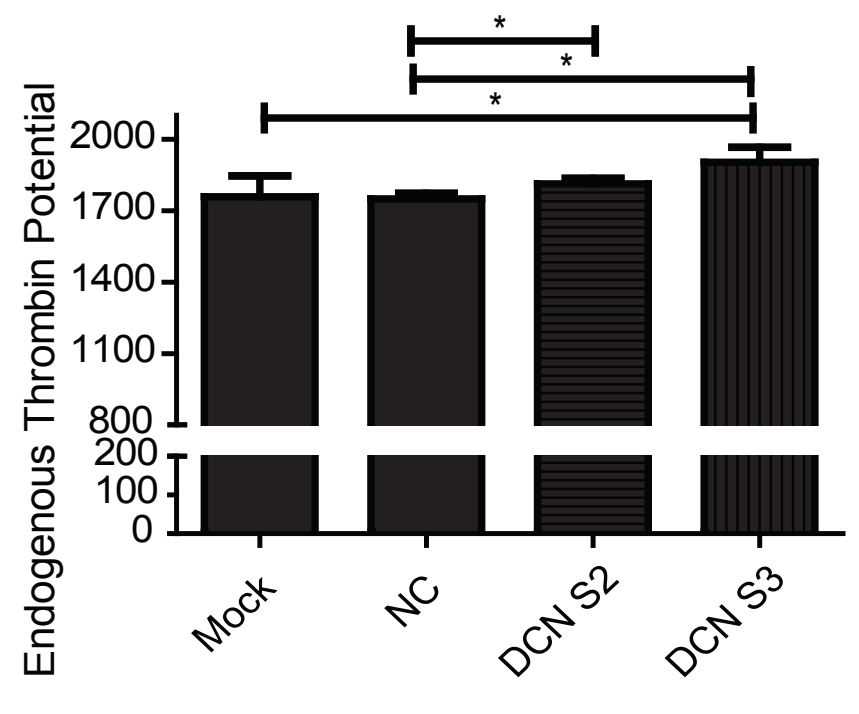


Figure 3

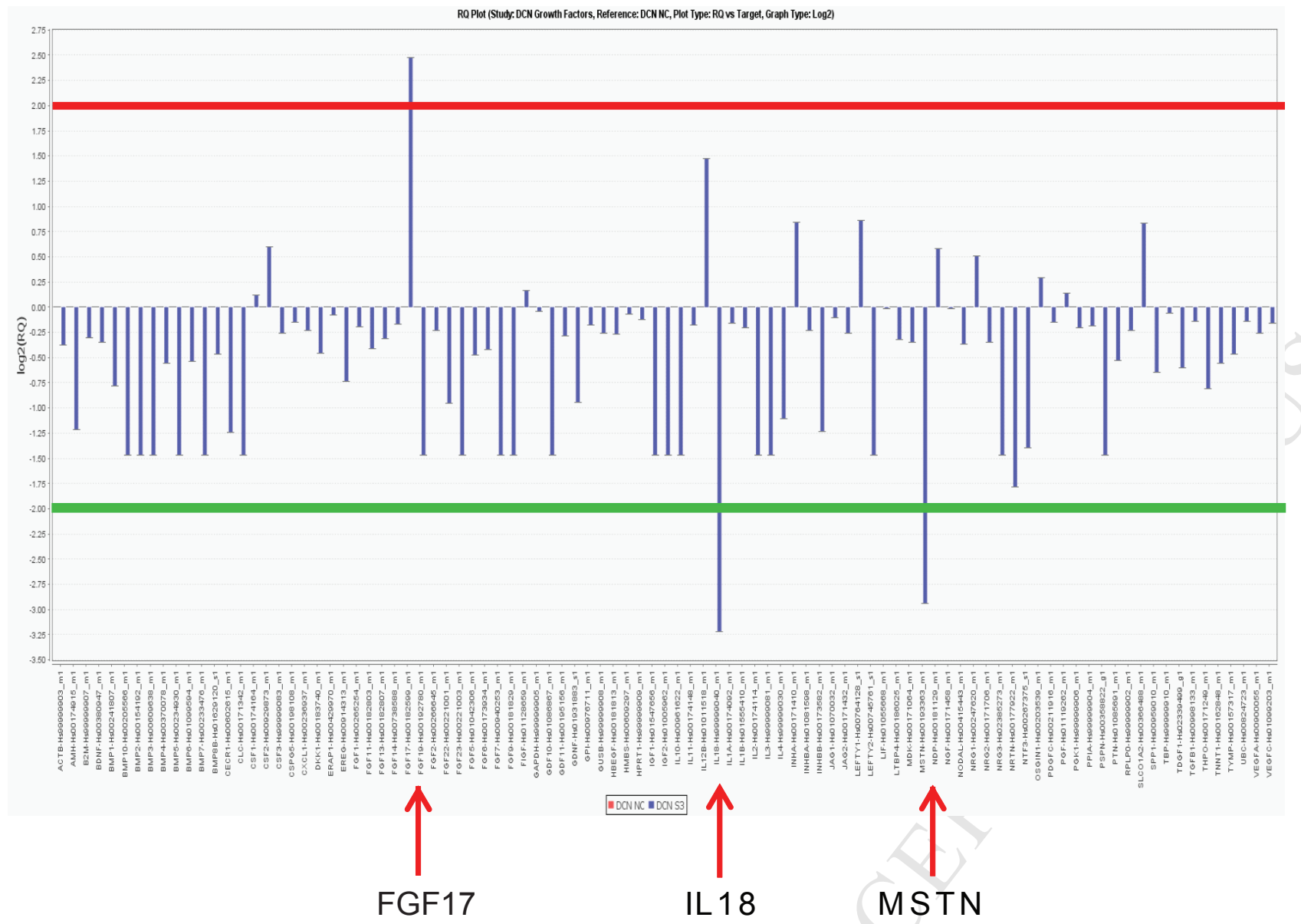


Figure 4

A.

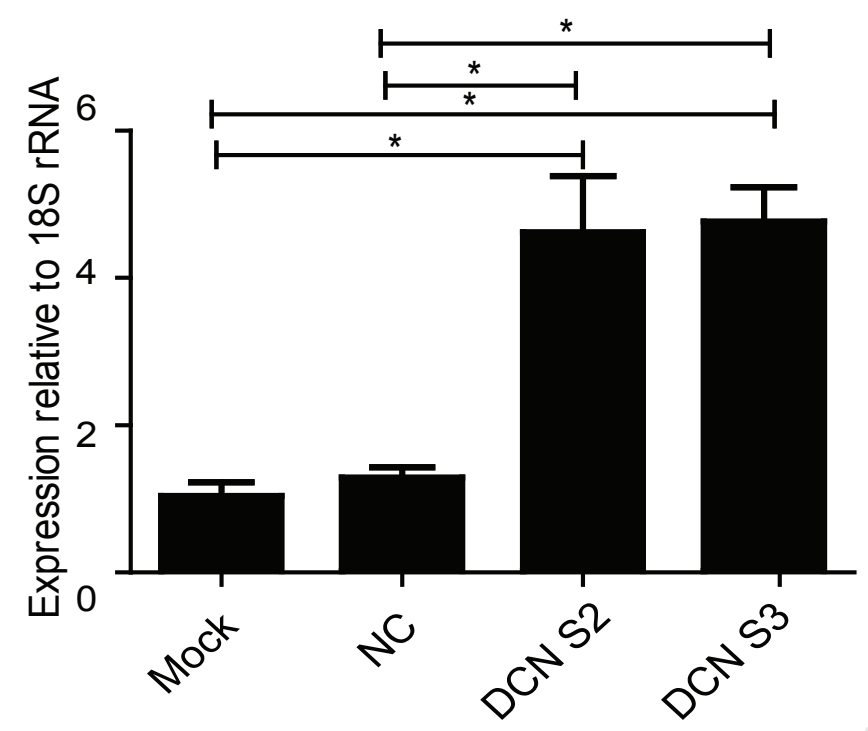

B.

MSTN

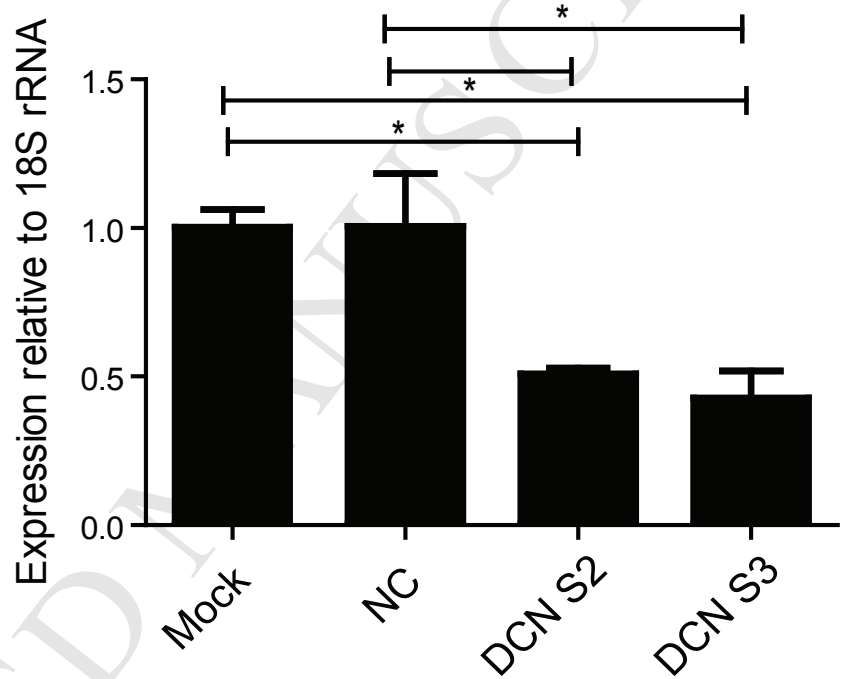


Figure 5

A.

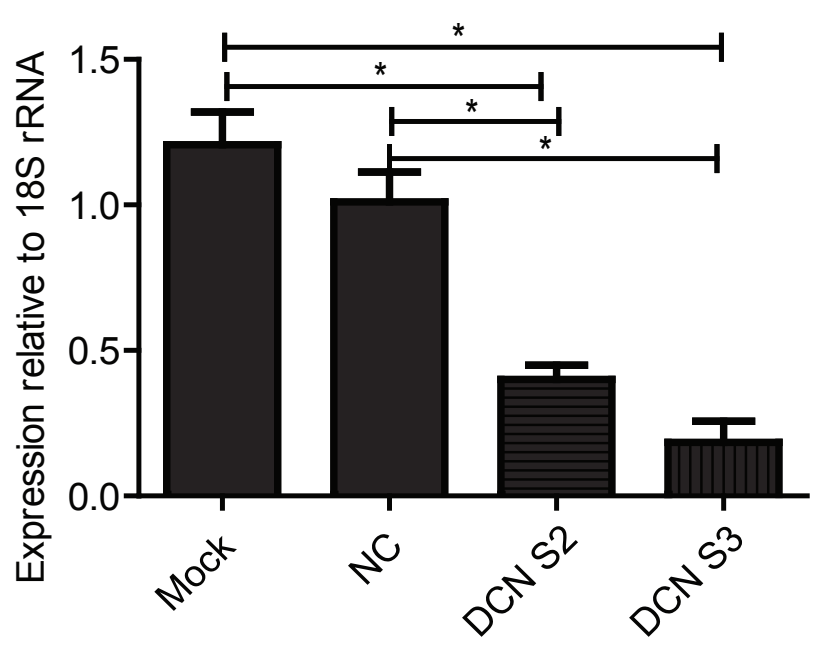

C.

EGFR

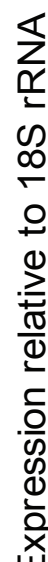

ய

E.

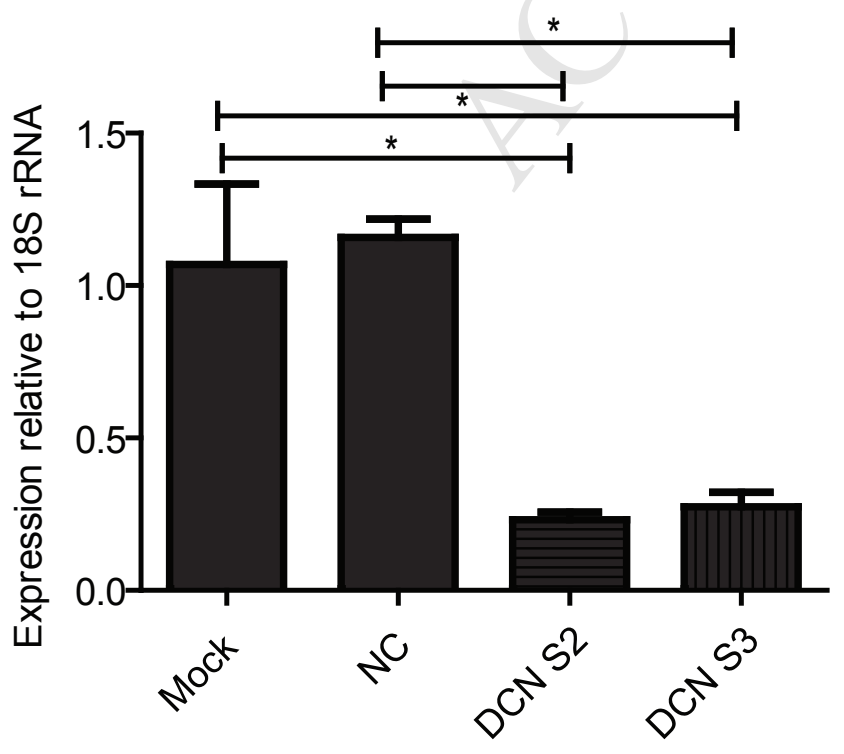

VEGFA

$E$
B.

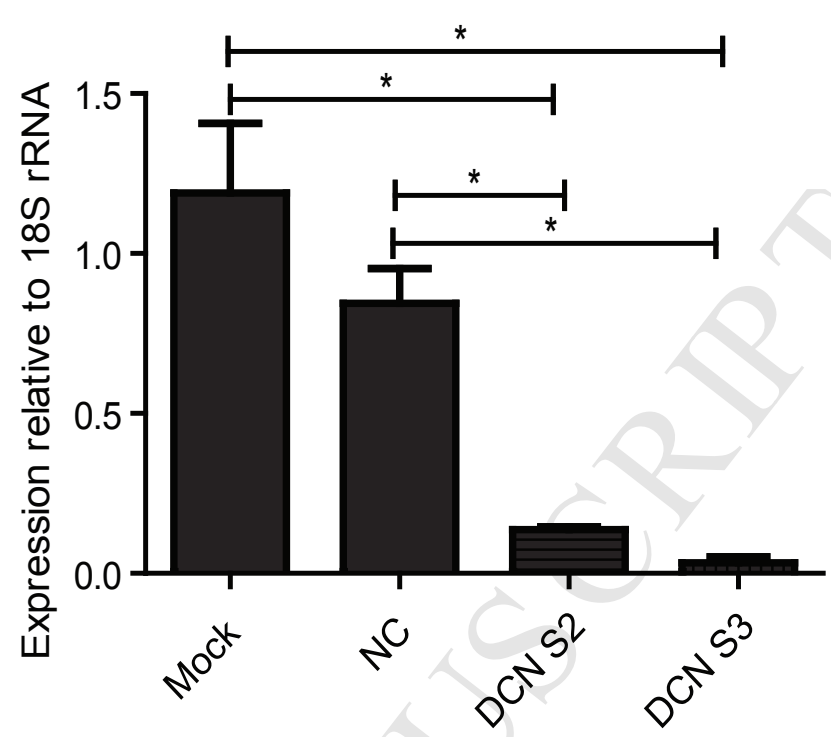

D.

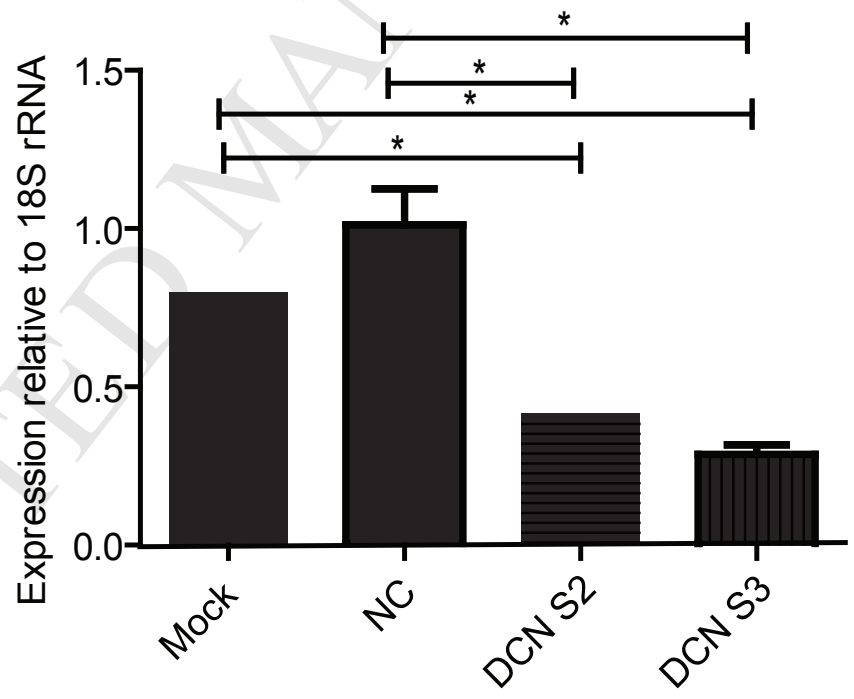


Figure 6

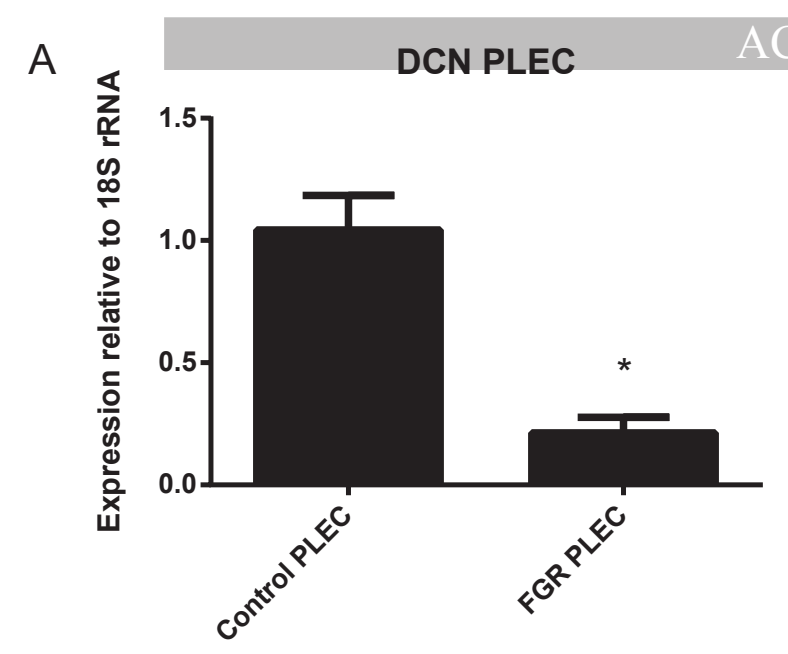

B

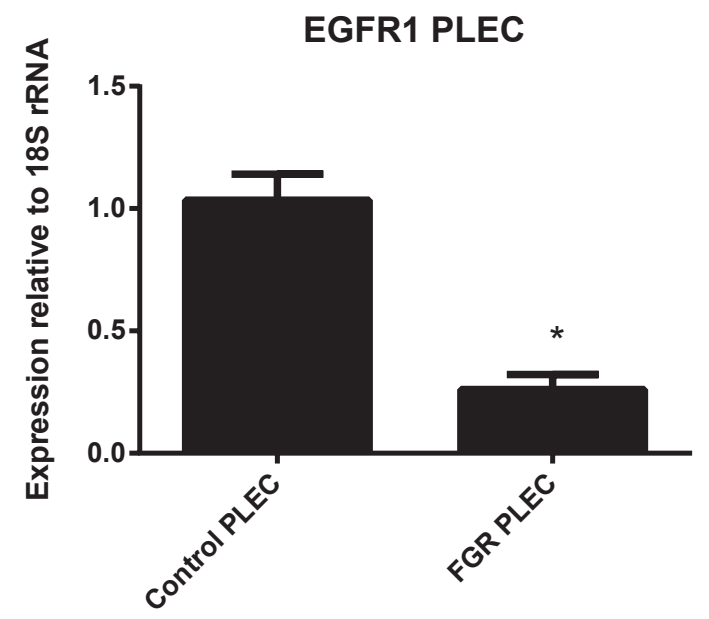

D

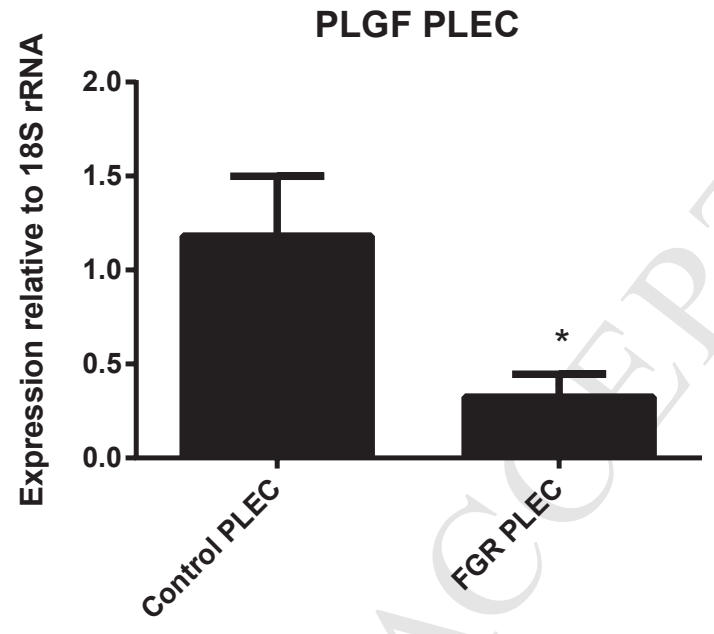

F

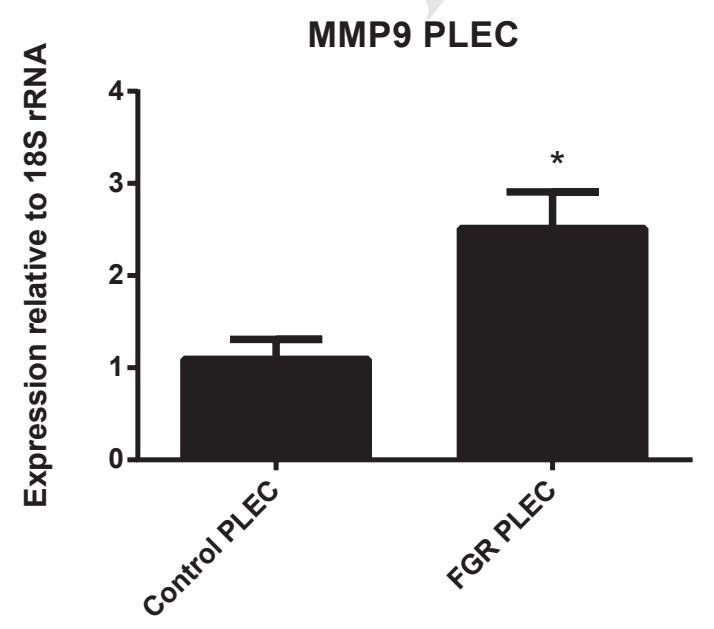

C

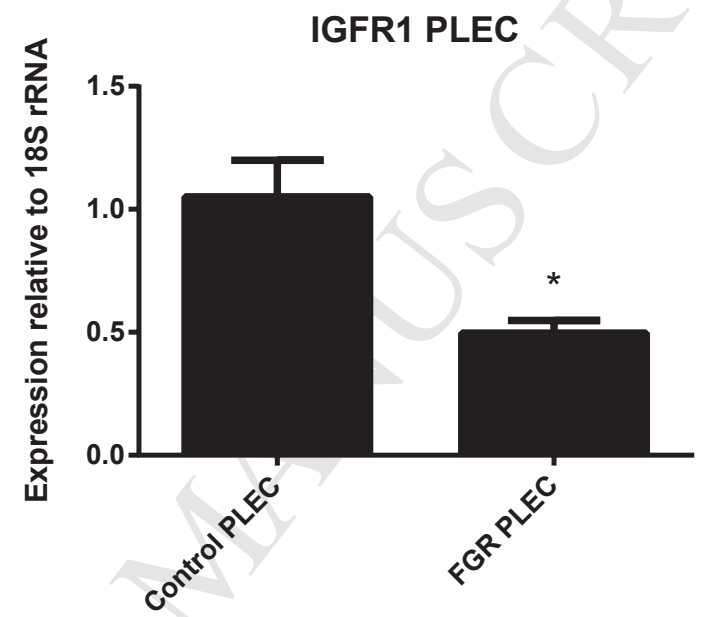

E

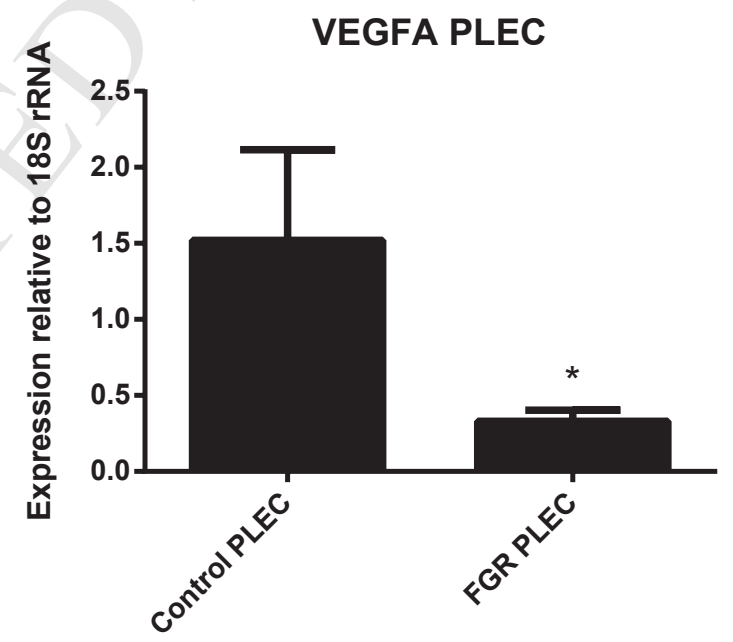




\title{
Altered Decorin Leads to Disrupted Endothelial Cell Function: A Possible Mechanism in the Pathogenesis of Fetal Growth Restriction?
}

\author{
Chui $A^{1}$, Murthi $P^{2,3}$, Gunatillake $T^{1,3}$, Brennecke S.P ${ }^{2,3}$, Ignjatovic ${ }^{4,5,6}$, Monagle \\ P.T ${ }^{4,5,6}$, Whitelock J.M ${ }^{7}$, and Said J.M ${ }^{1}$
}

\section{Supplementary Data}

\section{Materials and methods}

\section{Cell lines}

The human microvascular endothelial cell line from neonatal foreskin (HMVEC) was a kind gift from A. Prof. Grant Drummond (Department of Pharmacology, Monash University). HMVECs were grown in Microvascular Endothelial Cell Growth Medium2 (EGM-2 MV Single Quot Kit, catalogue number: CC-4147, Lonza/Clonetics, Victoria, Australia) containing $10 \%$ foetal bovine serum (FBS, Murdoch Children's Research Institute Tissue Culture Supplies, Victoria, Australia).

\section{Reduction of DCN expression by siRNA}

Four independent $D C N$ siRNA oligonucleotides were obtained as "4-For-Silencing siRNA Duplexes"TM (Qiagen, Victoria, Australia). The DCN siRNAs showed no significant DNA sequence similarity to other genes in GenBank cDNA databases (data not shown).

HMVECs were grown in EGM-2 MV and transfected with DCN siRNAs using HiPerfect transfection reagent (Qiagen, Victoria, Australia). Negative control (NC) siRNA consisted of a pool of enzyme-generated siRNA oligonucleotides of that were not specific for any known human genes (AllStars Negative siRNA, Qiagen, Victoria, Australia).

\section{RNA extraction and cDNA preparation}

Total RNA was extracted from cultured HMVECs using PureLink RNA Mini-kits (Lifesciences, Victoria, Australia), as per manufacturer's instructions.

Spectrophotometric analysis was used to determine the yield of total cellular RNA. Total cellular RNA was reverse-transcribed using Superscript III ribonuclease $\mathrm{H}$ reverse transcriptase (Invitrogen, Victoria, Australia) and cDNA was prepared in a two-step reaction using $2 \mu \mathrm{g}$ of total RNA.

\section{Real-Time PCR}

Quantification of DCN mRNA expression was determined by real-time PCR in an ABI Prism 7700 (Perkin-Elmer-Applied Biosystems, Victoria, Australia) as described previously [1]. Real-time PCR was performed using inventoried assays that consisted of a mix of unlabelled gene-specific PCR primers and TaqMan FAM labelled MGB probes (Applied Biosystems, Victoria, Australia). Gene expression quantification for the housekeeping gene 18S rRNA MGB endogenous control (Applied Biosystems, Victoria, Australia) was performed in the same well and was calculated according to the $2^{--\Delta \Delta C T}$ method [2]. 


\section{Western Immunoblotting}

Protein was homogenised and extracted from cultured HMVECs using RIPA Buffer

(Pierce, Victoria, Australia). Immunoblotting was performed as described elsewhere [1]. An affinity purified rabbit monoclonal antibody for DCN $(0.05 \mu \mathrm{g} / \mu \mathrm{l}$, Abcam, New South Wales, Australia), or rabbit monoclonal GAPDH (1ng/ml Imgenex, South Australia, Australia) was used as the primary antibody. Antibody binding was visualised using peroxidase-conjugated anti-rabbit or IgG-HRP secondary antibody (Dako, Victoria, Australia), following autoradiography using an enhanced chemiluminescence system (Amersham, New South Wales, Australia). The level of immunoreactive DCN protein relative to GAPDH was determined semi-quantitatively using scanning densitometry (Image Quant, New South Wales, Australia).

\section{HMVEC cell growth using xCELLigence}

HMVEC cell growth was assessed using the xCELLigence SP real-time system (Roche Diagnostics, Victoria, Australia) according to the manufacturer's instructions. Briefly, cells were prepared and added to the E-Plate 96 (Roche Diagnostics, Victoria, Australia). The xCELLigence system recorded the background electrical impedance for $72 \mathrm{~h}$. The results were analysed using the RTCA Software 1.2 (Roche Diagnostics, Victoria, Australia) and GraphPad Prism 5 (GraphPad Software, California, USA).

\section{HMVEC network formation assays}

HMVEC network formation was assessed using the $\mu$-Slide Angiogenesis system (IBIDI, Victoria, Australia). Briefly, $\mu$-Slide Angiogenesis wells were coated with $10 \mu \mathrm{l}$ of neat Growth-Factor Reduced Matrigel ${ }^{\mathrm{TM}}$ (BD, Victoria, Australia) and allowed to polymerise for $1 \mathrm{~h}$ at room temperature. HMVECs were then counted and resuspended in treatment media (media \pm siRNA) and seeded at a density of 8000 cells in $50 \mu \mathrm{l}$ total volume per well. The slide was returned to the incubator for $48 \mathrm{~h}$. The media was then removed, stained with calcien-AM (Millipore, Victoria, Australia) and visualised under a fluorescent microscope. Photomicrographs of entire wells were taken in triplicates and branch points were counted by Wimasis Image Analysis.

\section{Thrombin Generation Assays}

HMVECs were plated into 96 well plates at a density of 5000 cells per well and transfected with DCN siRNAs and controls for $48 \mathrm{~h}$. Venous blood was collected from healthy blood donors $(n=40)$ and Platelet Poor Plasma (PPP) was obtained. Measurement of endogenous thrombin potential (ETP) by Calibrated Automated Thrombogram (CAT, Thrombinoscope, Stago Diagnostica, Victoria, Australia) was performed according to manufacturer's instructions. All experiments were conducted in triplicate wells. The endogenous thrombin potential (ETP) represents the total enzymatic activity performed by thrombin and is generally considered the most predictive parameter of bleeding/thrombosis risk [3, 4]. The ETP (nM/minute) was calculated using the Thrombinoscope software version 3.0.0.29 (Stago Diagnostica, Victoria, Australia) and represents the area under the thrombin generation curve.

\section{Human Growth Factors PCR Array}

The "Human Growth Factor" Taqman PCR array (Applied Biosystems, Victoria, Australia) for gene profiling was used to screen for downstream target genes of $D C N$, 
according to manufacturer's instructions. The plate contained 84 gene-specific primer sets and a panel of five housekeeping gene primers for normalisation (18S rRNA, B2M, HPRT1, GAPDH and ACTB). The relative gene expression values, or fold changes, were analysed using DataAssist Software v3.0 (Applied Biosystems, Victoria, Australia) and normalised to the average $C_{t}$ value of the five housekeeping genes. Candidate genes were prioritised based on level of gene expression i.e. at least 2-fold change in mRNA expression in siRNA treated cells when compared with NC.

\section{References}

[1]. Chui A, Zainuddin N, Rajaraman G, Murthi P, Brennecke SP, Ignjatovic V, et al. Placental syndecan expression is altered in human idiopathic fetal growth restriction. Am J Pathol. 2012;180(2):693-702. Epub 2011/12/06.

[2]. Livak KJ, Schmittgen TD. Analysis of relative gene expression data using real-time quantitative PCR and the 2(-Delta Delta $\mathrm{C}(\mathrm{T})$ ) Method. Methods. 2001;25(4):402-8.

[3]. Castoldi E, Rosing J. Thrombin generation tests. Thromb Res. 2011;127 Suppl 3:S21-5. Epub 2011/01/26.

[4]. Duchemin J, Pan-Petesch B, Arnaud B, Blouch MT, Abgrall JF. Influence of coagulation factors and tissue factor concentration on the thrombin generation test in plasma. Thromb Haemost. 2008;99(4):767-73. Epub 2008/04/09. 